\title{
HOW TO RATIONALIZE THE EXPORT-SAVING PARADIGM (the Czech experience)
}

\author{
Bruno S. SERGI, * Karel VÍT **
}

\begin{abstract}
:
The paper analyzes the relationship between saving and export in the Czech economy. Because the Czech economy has been increasingly trading with Western Europe, testing the relationship between these two variables is significant. OLS and 2SLS are applied to quarterly data between gross national savings, gross domestic product and exports over the period $1994-2001$. The 2SLS procedure has also the advantage of identifying the underlying principles of the formal paradigm by means of instruments (productivity, real investments and unemployment). This study does lend support to the paradigm advanced by Maizels in 1968, which relates a country's increase in domestic savings to exports.
\end{abstract}

Keywords: exports and savings, the Maizels' hypothesis, Czech economy

JEL Classification: D10, E12, P44, P35

\section{Introduction}

The move of ex-Soviet block's members to market economies is shaping a part of economic research nowadays. These recent market economies are rethinking domestic economic organizations and methods of production since the late eighties in an attempt to abandon paternalistic-type systems definitively and to enhance competitiveness (see Sergi, 2003a). Following outward-orientation economic approach, outcomes of this transformation process are exhibiting trade and financial linkages with western markets. While a larger flow of foreign direct investment is another decisive feature of this transformation process, larger trade flows give rise to the possibility that domestic markets can earn excess savings by taking advantage of exports.

The importance of this line of research that we propose in this paper concerning one of the most advanced transition economy in East Central Europe is twofold.

*) University of Messina, Faculty of Political Science, Via Tommaso Gannizzaro 9, 98122 Messina, Italy (e-mail: bsergi@unime.it).

${ }^{\star \star}$ ) University of Economics, 4, W. Churchill Sq., CZ - 13067 Prague 3 (e-mail: vit@ vse.cz).

$\left.{ }^{\star \star \star}\right)$ We wish to thank Bojka Hamerníková, Květa Kubátová, Vratislav Izák and two anonymous referees of this review for helpful comments and suggestions on earlier drafts of this paper. We assume responsibility for any remaining errors. Part of this research was undertaken when the first author was a visiting professor at the University of Economics Prague in September - October 2002. 
First, it fills a gap in the literature having not yet analyzed in deep such a relationship; in fact, this is an ignored area of research. Second, an underlying principle of the statistical association between exports and savings has to be advanced. This was stressed earlier by Bhagwati (1978) when he argues "there is little evidence so far for some of the hypotheses that could provide a rationale for such an association implying a causal relationship running from export to savings" (1978, p. 147). That is, the modelling of the saving function as in the old Keynesian fashion may partially represent what the new market post-communist countries are experiencing. From one theoretical point of view, higher saving rates are conducive to an enduring growth, which is the ultimate goal of the economic transformation, but the rationale implying a causal relationship has to be advanced yet.

An increasing relationship with Western Europe (see, for example, Winiecki, 2000), which is contributing with larger import from the east is contributing to transition countries' export and gross domestic product (GDP). It introduces the enquiry into the relationship between the external sector and domestic savings and next whether the external sector may contribute to raising domestic savings. Therefore, the focus on the export-saving function seems a worthy topic of study. Although Maizels' (1968) has advanced this rationale for the developing countries - the hypothesis comes under the heading of the "Maizels' hypothesis" and relates a boost to national savings from export - it is worth exploring it in the light of recent developments in Central Europe. In the past, researchers have found support to the Maizels' hypothesis, but in doing so they have used data for developing countries of Latin America and Africa (see Kim, 1990; Sinha, 1998, 1999; Wilbur and Haque, 1992). Only recently one study attempted to test the relationship between savings and exports in the Slovak economy, which supports the Maizels' view (see Sergi, 2003b). Thus, this paper contributes to the mounting literature on the transition economies of Central Europe by introducing and testing the "Maizels' hypothesis". In addition, this paper aims to advance a rationale for such a relationship studying the Czech case.

Motivated by the recognition of export as a key variable in saving determination, this paper seeks to explain how export becomes part of the transformation process in the Czech Republic. The paper is structured as follows. We revisit the saving function as proposed by Maizels (1968) and outline the key aspect of the research into this topic. This will be followed by the methodological approach and reported ordinary least-squares (OLS) regression to estimate short-run equilibrium relationship and two-stage least squares (2SLS) procedure to appraise the rationale concerning the link export saving. Section 4 will present conclusions.

\section{The Maizels' Hypothesis of Saving Function}

The trade linkages of Central European countries are reorienting westwards. In an outward orientation of their economic growth, data evokes a "natural" trade linkage (see Piazolo, 2001) and a process of trade "reorientation" in the direction of the European Union's markets. Winiecki (2000) explains this process as a "return to normality in foreign trade", by which the enterprises' system started to correct the inherited microeconomic distortions. In fact, larger trade ties with the west produce more microeconomic and macroeconomic efficiency, and through the multiplier, they effect income either. Besides, a shift in the aggregate saving schedule that can take place because the propensity to save is conceivably larger in the export sector respect to the other sectors, although this fact induces the latter to increase the marginal propensity to save. Furthermore, the government should be able to rely heavily on taxes on international trade. 
Given the importance of export-saving issues to the current study, it is important that we set out the principles that have guided previous research. This variety of aspects spurs to compare the two alternative hypotheses of saving behaviour and test data econometrically. In the standard Keynesian saving function, overall savings are related to income and this relationship can be modelled as follows:

$$
\text { In } s_{t}=\alpha_{0}+\alpha_{1} \ln y_{t}+\varepsilon_{\mathrm{t}}
$$

where $s_{t}$ is saving, $y_{t}$ is income and $\varepsilon_{t}$ is the error term. The Maizels' specification can be written as:

$$
\text { In } s_{t}=\beta_{0}+\beta_{1} \ln x_{t}+\beta_{2} \ln (y-x)_{t}+v_{t}
$$

where $s_{t}$ is gross national saving, $x_{t}$ is export, $y_{t}-x_{t}$ is the gross domestic product minus export and $n_{t}$ is the error term; $\alpha_{0}$ and $\beta_{0}$ are two constants. Thus, while equation 1 enters with the overall GDP as the explanatory variable, equation 2 breaks up the GDP into two components, export and non-export component of GDP. The coefficient attached to the export component of GDP, i.e. $\beta_{1}$, explains the direct effect of export on the saving schedule, as in the original contribution advanced by Maizels, and its null hypothesis should be $H_{0}: \beta_{1} \leq 0$.

\section{Methodology and Data}

Quarterly data for the variables expressed in equation (2) were taken from the International Monetary Fund's International Financial Statistics (various issues). All series begin in the first quarter 1994 and end in the third quarter 2001. Variables are transformed in real terms by means of the consumer price index and seasonally adjusted by the additive method. It is employed standard OLS regression technique to estimate short-run equilibrium relationship. A 2SLS procedure appraises the rationale concerning the link export saving. First step is the OLS regression to test the saving function in equation (2).

Table 1

Maizels' Saving Function Specification

\begin{tabular}{|l|c|}
\hline & Maizels' specification \\
\hline Constant & $0.15(0.11)$ \\
$x_{t}$ & $0.72(3.11)$ \\
$y_{t}-x_{t}$ & $0.13(3.68)$ \\
Adjusted $R^{2}$ & 0.32 \\
DW & 0.83 \\
F-stat. & 7.08 \\
Ramsey's Reset test $\chi^{2}(1)$ & 1.57 \\
\hline
\end{tabular}

Notes: Variables are in logs and results of the saving function as specified by the underlying equation (2). $t$-values are reported in parentheses. Quarterly data spans from 1994:Q1 to 2001:Q3.

This stage involves clarifying the precise relationship between dependent and independent variables. The coefficient attached to export has the expected sign and is statistically significant (see Table 1). In addition, the non-export component proves statistically significant, but the coefficient is small $(0.13)$ when in comparison with the coefficient of export (0.72). The Durbin-Watson (DW) test for first-order serial correlation in the residuals exhibits evidence of serial correlation. As concerns the goodness of the regression, the adjusted $R^{2}$ is low $(0.32)$. The diagnostic tests 
done on the residuals do not evidence functional form misspecification at the 5 per cent level of significance. The uncomfortable aspect of this regression is the low adjusted $R^{2}$ and the DW statistic; the second step of our approach has the goal of eliminating these deficiencies by supplying foundation to the underlying export saving paradigm.

This specification is examined further by using 2SLS procedure, which enables to obtain consistent estimates of the parameters of the regression model when they violate the assumption of orthogonality (see Hušek, 1999). Here the results are more reassuring because we are not simply interested in the signs of coefficients and their statistical significance, but in the nature of this relationship as well. This motivates the use of a 2SLS procedure. Initially, there is the advantage of permitting the estimation of a single equation derived from a simultaneous equation system. Then, all the predetermined variables of the simultaneous equation model are specified as instrumental variables. That is, the idea behind the instrumental variable approach is to find a set of variables (instruments), which are correlated with the explanatory variables and uncorrelated with the disturbances and be able to eliminate the correlation between right-hand side variables and the disturbances. The 2SLS involves two specific stages. The first finds the portions of the endogenous and exogenous variables that can be attributed to the use of instruments. This stage involves estimating an OLS regression of each variable in the model on the set of instruments. The second stage regresses the original equation, where the fitted values from the first-stage regressions replace all variables; the coefficients of this regression are the 2SLS estimates. Results from estimating equation (2) with a set of instruments appear in Table 2.

Table 2

\section{A 2SLS Procedure and Maizels' Saving Function Specification}

\begin{tabular}{|l|c|c|c|c|}
\hline Instruments & \multicolumn{2}{|c|}{$\begin{array}{c}\text { Productivity, real investments, } \\
\text { unemployment, constant }\end{array}$} & \multicolumn{2}{c|}{$\begin{array}{c}\text { Productivity, real investments, } \\
\text { unemployment }\end{array}$} \\
\hline Variables & coefficient & t-statistic & coefficient & $t$-statistic \\
\hline Constant & -1.55 & -1.09 & - & - \\
$x_{t}$ & $0.89^{*}$ & 2.13 & $0.64^{*}$ & 2.15 \\
$y_{t}{ }^{-} x_{t}$ & 0.61 & 1.46 & 0.47 & 1.39 \\
$R^{2}$ & -0.84 & & -0.38 & \\
$R^{2}$ adj. & -0.98 & & -0.43 & \\
$F$-stat. & 2.41 & & 5.02 & \\
DW & 2.63 & & 2.46 & \\
\hline
\end{tabular}

Note: Although the $R^{2}$ statistic ranges from 0 to 1 , in the 2SLS procedure the $R^{2}$ and the adjusted $R^{2}$ can be negative.

Our instruments are productivity, real investments and unemployment (Table 2 reports results with and without the intercept). These instruments were chosen to reflect likely explanation of the export performance of the Czech economy and the effect on labour markets as well. The 2SLS shows that the coefficient attached to export is positively signed and statistically significant. By contrast, the domestic component of GDP, i.e. $y_{t}-x_{t}$, exhibits no significance. Overall, this set of results is consistent with the Maizels' hypothesis and reveals the nature of larger export flows due to the working of the three instruments employed in the analysis. A more productive and competitive economy can offer a broader understanding of what is driving the result of larger trading ties with the west and the resulting relationship with 
gross domestic saving. While the empirical literature pays no significant attention to theoretical justification, we show how allowing for instruments provides a much more useful interpretation.

\section{Conclusion}

As introduced earlier in the paper, an entirely new market strategy is effecting the economic thinking and applied research concerning post-communist countries. Policymakers are endorsing more stable systems, but also the integration of domestic economies into European and world markets has to be scrutinised. Central European economies have shifted trading partnership to the west and rather trade is becoming increasingly relevant in determining the evolution of GDP and overall domestic economic strategies. It follows that it is meaningful to investigate the relationship between exports and savings in those countries of Central Europe that are more advanced as for the degree of economic transformation and the intensity of economic links with the west.

To put it simply, this topic has a particular resonance to be studied because is conceivable that this new economic "framework" may entail importance to boosting domestic savings and enhancing economic growth. While there is a burgeoning literature on the many aspects of transition economies, the relationship between savings and exports has been a neglected area of research. Previous research has simply viewed the saving function in the light of the Keynesian theory, which predicts a relationship between saving and GDP, while to date little case study research has been produced on alternate saving functions. Concerning this alternate explanation of the saving function, previous studies have used data for developing countries of Latin America and Africa and only one study attempted to test the relationship between saving and export for Slovakia. Following earlier attempts, this paper has examined this issue by relating the saving function to the export component of gross domestic product and it comes under the heading of the Maizels' hypothesis. Some researchers have already found support to such a hypothesis, which states that export can strongly contribute to the generation of saving. We have tested the hypothesis of export saving and verified that there is a rationale for such an association implying a causal relationship running from export to savings. Evidence consistent with the Maizels' hypothesis that other researchers have supported is found. Specifically, this study has applied standards OLS regression and the 2SLS method over the period $1994-2001$. The results showed that the export coefficient is positive and statistically significant. Furthermore, whilst the non-export component of GDP shows a statistically significant coefficient in the OLS (though the coefficient is small), the coefficient loses statistical significance when the alternate 2SLS procedure is employed.

All told, the observation made by Bhagwati that there is little evidence for the hypotheses that could provide a rationale for a relationship running from export to savings has stimulated out interest in conducting this research, though this stimulates our interest for continued research.

References

Hušek, R. (1999), Econometric Analysis (in Czech). Prague: Ekopress.

Kim, K. J. (1990), "Export and Saving in Developing Countries." Journal of Economics, 16, pp. 175178. 
Maizels, A. (1968), Exports and Economic Growth of Developing Countries. Cambridge, MA: Cambridge University Press.

Piazolo, D. (2001), The Integration Process between Eastern and Western Europe. Berlin and Heidelberg: Springer-Verlag.

Sergi, B. S. (2003), Economic Dynamics in Transitional Economies: The Four-P Governments, the EU Enlargement, and the Bruxelles Consensus. New York, London and Oxford: International Business Press(a).

(2003), "Testing the Saving Functions of Keynes and Maizels. A Case Study on Slovakia." Eastern European Economics, 41(2), pp. 60-69(b).

Sinha, D. (1998), "Tests of the Maizels' Hypothesis for Latin American Countries." Studies in Economics and Finance, 19(1), pp. 103-118.

(1999), "Do Exports Promote Savings in African Countries?" Economia Internazionale, 52(3), pp. 383-395.

Wilbur, W. L., Haque, M. Z. (1992), "An Investigation of the Export Expansion Hypothesis." Journal of Development Studies, 28(2), pp. 297-313.

Winiecki, J. (2000), "Solving Foreign Trade Puzzles in Post-Communist Transition." Post-Communist Economies, 12(3), pp. 261-278. 